\title{
Macrovascular and microvascular dysfunction in the metabolic syndrome
}

\author{
Sébastien Czernichow ${ }^{1,2}$, Jerry R Greenfield ${ }^{3,4}$, Pilar Galan ${ }^{1}$, Fatima Jellouli ${ }^{1}$, Michel E Safar ${ }^{5}$, Jacques Blacher ${ }^{5}$, \\ Serge Hercberg ${ }^{1,2}$ and Bernard I Levy ${ }^{6}$
}

The metabolic syndrome (MetS) is associated with increased risk of type-2 diabetes and cardiovascular disease (CVD). We hypothesized that both small and large arteries may be impaired in subjects with the MetS, even in the absence of known CVD or diabetes. We compared both skin capillary density (CD) and pulse-wave velocity (PWV) in 36 cases with the MetS with those from 108 age- and gender-matched controls from the SU.VIM.AX-2 cohort. Compared with controls, MetS subjects demonstrated increased PWV $\left(12.2 \pm 2.8\right.$ vs. $\left.10.7 \pm 1.9 \mathrm{~m} \mathrm{~s}^{-1}, P=0.005\right)$ and lower functional CD $(83.1 \pm 15.7$ vs. $89.4 \pm 14.2$ capillaries per $\mathrm{mm}^{2}, P=0.03$ ). Functional $C D$ was inversely related to fasting glucose, triglycerides (TGs) and HOMA-IR (all $P<0.05$ ). On the other hand, no association was found between CD and BP or with PWV. In multivariate models, the odds ratios (95\% confidence interval) for one standard deviation change, for having an impaired PWV ( $\geqslant 12 \mathrm{~m} \mathrm{~s}^{-1}, n=44$ ), were: 1.65 (1.11-2.45) for systolic BP and $1.93(1.25-2.99)$ for TG only. For impaired $C D\left(\leqslant 80\right.$ capillaries per $\left.\mathrm{mm}^{2}\right)$, the odds ratios (95\% confidence interval) were $1.45(1.00-2.08)$ for TG and 1.65 (1.13-2.43) for fasting glucose, only. In conclusion, MetS subjects exhibited evidence of macro- and microcirculatory dysfunction, even in the absence of diabetes and CVD. The common mechanism linking MetS components to CVD risk through small- and large-artery dysfunctions may be mediated through metabolic factors related to insulin resistance, not to increased BP.

Hypertension Research (2010) 33, 293-297; doi:10.1038/hr.2009.228; published online 15 January 2010

Keywords: arterial stiffness; capillary density; metabolic syndrome; microcirculation

\section{INTRODUCTION}

The metabolic syndrome (MetS) is a cluster of cardiometabolic abnormalities associated with increased risk of type-2 diabetes and cardiovascular disease (CVD). ${ }^{1}$ According to the International Diabetes Federation (IDF) criteria, the MetS is defined as increased waist circumference (WC) plus any two of the following four factors: triglyceride (TG) level $\geqslant 1.7 \mathrm{mmoll}^{-1}$, high-density lipoproteincholesterol $<1.03 / 1.29 \mathrm{mmoll}^{-1}$ (males/females) or treatment with hypolipidemic therapy, systolic/diastolic BP $\geqslant 130 / 85 \mathrm{~mm} \mathrm{Hg}$ or treatment for hypertension, and fasting plasma glucose $>5.6 \mathrm{mmoll}^{-1}$ or previously diagnosed type- 2 diabetes. ${ }^{2}$ Although the pathways linking components of the syndrome to increased cardiovascular risk remain unknown, various intermediates have been proposed, such as intimamedia thickness or arterial stiffness..$^{3-7}$ Indeed, previous studies report deleterious relationships between central fat accumulation and the structure and function of large arteries. ${ }^{8-11}$

The microcirculation is generally defined as the network of small arteries, arterioles capillaries and venules that serve metabolic and other tissues. ${ }^{12-14}$ Microcirculatory dysfunction has been proposed to be an additional mechanism relating obesity to CVD, through insulin resistance and hypertension. ${ }^{15}$ Reduced capillary blood flow may contribute to the development of insulin resistance in muscle and other organs. ${ }^{15,16}$ Cytokines originating in adipose tissue, particularly the visceral fat depot, might contribute to insulin resistance and CVD through their adverse impact on blood flow regulation in the microcirculation. It has even been proposed that cytokines from perivascular fat depots may also play a role. ${ }^{17}$ Only one previous study has specifically examined the independent relationship between the MetS per se and capillary density (CD). ${ }^{18}$ However, no study has simultaneously examined the impact of the MetS on small- and largearterial function.

The cutaneous circulation may be considered a representative of the microcirculation of most vascular beds, particularly muscles. ${ }^{19}$ The aim of this study was to simultaneously examine small- (functional and anatomical skin $\mathrm{CD}$ ) and large (pulse-wave velocity, PWV)-artery function in subjects with and without the MetS. We also investigated

${ }^{1}$ Nutritional Epidemiology Research Unit, UMR U557 INSERM, U1125 INRA, CNAM, Paris 13, CRNH-IdF, Bobigny, France; ${ }^{2}$ Public Health Department, Avicenne Hospital (AP-HP), Paris 13 University, Bobigny, France; ${ }^{3}$ Diabetes and Obesity Research Program, Garvan Institute of Medical Research, Sydney, Australia; ${ }^{4}$ Department of Endocrinology and Diabetes Centre, St Vincent's Hospital, Sydney, Australia; ${ }^{5}$ Hypertension Unit, Hôtel-Dieu Hospital (AP-HP), Paris-Descartes University, Paris, France and ${ }^{6}$ Department of Physiology and non-invasive investigations, Lariboisière Hospital (AP-HP) and PARC, INSERM U970, Paris, France

Correspondence: Professor S Czernichow, Faculté de médecine SMBH, Nutritional Epidemiology Research Unit INSERM U557; U1125 INRA; CNAM; UP13, 74 rue Marcel Cachin, Bobigny 93017, France.

E-mail: czernichow@uren.smbh.univ-paris13.fr

Received 6 July 2009; revised 19 November 2009; accepted 3 December 2009; published online 15 January 2010 
the associations between each component of the MetS and these vascular markers, and the risk associated with impairment in either PWV or CD.

\section{METHODS}

\section{Subjects and study design}

The SU.VI.MAX study (1994-2002) was a prevention trial designed to test the efficacy of antioxidant supplementation on ischemic heart disease and cancer. ${ }^{20}$ Since 2006, 7200 subjects have agreed to be followed-up in SU.VI.MAX-2, an observational prospective cohort study, with the aim of exploring the associations between diet and aging in France. A specific sub-protocol was designed to assess microcirculation parameters in the participants of the SU.VI.MAX-2 cohort living in the Paris area and the sample was restricted to those without a history of cancer or CVD events since 1994.

MetS was defined according to the International Diabetes Federation (IDF) criteria described above. ${ }^{2}$ Similar numbers of subjects with and without the MetS were taking hypolipidemic therapy (15 vs. 6\%, respectively) or antihypertensives ( 1 vs. 6\%). None of the subjects were taking antidiabetic medication. Thirty-six subjects with the MetS were matched for age and gender with three controls $(n=108)$ and were studied at the Department of Physiology and non-invasive Investigations (Hôpital Lariboisière, Paris, France) between November 2006 and July 2007. A total of 141 individuals had all variables without missing data.

\section{Microvascular assessment}

Intravital video capillaroscopy allows visualization of the skin in real-time. In combination with video and computer technology, capillaroscopy generates high-contrast numeric images of dermal capillaries. Capillaroscopy was performed using a standardized validated technique detailed elsewhere. ${ }^{21,22}$ Briefly, individuals were studied between 0800 and 1200 hours after an overnight fast. They were asked not to smoke from the previous evening. The dorsum skin of the middle phalanx of the non-dominant hand was examined. An approximately $3 \times 3$-mm skin area on the middle third of the phalanx was defined. Four microscopic fields $\left(1 \mathrm{~mm}^{2}\right.$ each) were randomly chosen for recording and measurements. Mean CD was defined as the number of capillaries per unit area of skin and was calculated as the mean of four measurements performed for each subject. For each subject, images were acquired at baseline to quantify the total number of continuously erythrocyte-perfused capillaries per dermal surface unit (functional $\mathrm{CD}$ ), and during venous congestion (by applying a cuff to the wrist and maintaining a $50-\mathrm{mm} \mathrm{Hg}$ inflating pressure for $2 \mathrm{~min}$ ), in order to obtain the maximal response of all existing capillaries and to assess structural (anatomical) CD. A previous study has shown that intra-observer and inter-observer repeatability was 4.3 and $5.9 \%$, respectively. ${ }^{21}$ Capillary recruitment was defined as percentage of the baseline value.

\section{Hemodynamic anthropometric and body composition measurements}

Brachial blood pressure (BP) and heart rate were measured in the sitting position using a semi-automatic oscillometric device (Dinamap PRO 400V2; General Electric, Waukesha, WI, USA) using an appropriate cuff size. After $10 \mathrm{~min}$ of rest, two measurements in each arm were obtained at 5-min intervals. Systolic and diastolic BP were calculated as the mean of the second measurements obtained from the left and right arm. Mean arterial pressure was calculated as (DBP)+(SBP-DBP)/3. PWV (PWV) and central aortic BP were derived from radial artery pressure wave measured with a SphygmoCor system (PWV Medical, Sydney, Australia). ${ }^{23-25}$

Anthropometric data were obtained using a Tanita DC-320 bio-impedance analysis device (Tanita Corp., Tokyo, Japan) using four separate foot-pad electrodes mounted on the system's base, with subjects in indoor clothing and no shoes. ${ }^{26}$ Percent body fat (\%BF=fat mass/body weight) and visceral fat level (arbitrary unit) are presented. WC was measured as the circumference midway between lower ribs and iliac crests. ${ }^{27}$

\section{Biochemical measurements}

Serum cholesterol and TG concentrations were measured using standard methods. Fasting plasma glucose was assayed enzymatically (hexokinase) using a multiparametric analyzer (C8000 Architect Abbott analyzer, Rungis, France). Fasting plasma insulin was measured by microparticle enzyme immunoassay (Axsym Abbott analyzer). Insulin resistance was estimated by calculating the HOMA-IR index (fasting plasma insulin $\times$ fasting plasma glucose) $/ 22.5$.

\section{Statistical analyses}

Data are expressed as mean \pm s.d. for continuous variables and percentage for categorical variables. Comparisons between the two groups were performed using unpaired $t$-tests or $\chi^{2}$-tests. Multivariate independent associations between adiposity measures (BMI, WC, \%BF, VAT), biological markers (fasting plasma glucose, insulin, HOMA-IR) and both PWV and CD were assessed using age- and gender-adjusted linear regression models. Correlation coefficients $(\beta)$ are presented for each independent model. Logistic regression was performed to investigate the independent predictors of impaired PWV $\left(\geqslant 12 \mathrm{~m} \mathrm{~s}^{-1}\right)$ and functional $\mathrm{CD}\left(\leqslant 80 \mathrm{nmm}^{-2}\right)$. Odds ratios with $95 \%$ confidence intervals are presented, indicating the risk for increase in one standard deviation for each continuous component of the MetS in both ageand gender-adjusted and multivariate models. Variables were included in the multivariate models if they reached a significance level of less than 0.05 in the age- and gender-adjusted models. For all analyses, statistical significance was judged at $\alpha<0.05$. All statistical analyses were performed using SAS version 8.2 (SAS, Cary, NC, USA).

\section{RESULTS}

The characteristics of the population are shown in Table 1. As expected, body mass index (BMI), WC, trunk fat and visceral adipose tissue (VAT) were significantly higher in subjects with the MetS. Fasting plasma glucose, insulin and HOMA-IR were also higher in the MetS group.

As shown in Table 2, subjects with MetS exhibited a more deleterious hemodynamic phenotype compared with subjects without the syndrome. Central BP and PWV $\left(12.2 \pm 2.8\right.$ vs. $10.7 \pm 1.9 \mathrm{~m} \mathrm{~s}^{-1}$, $P=0.0047)$ were significantly higher in MetS subjects. Functional CD was significantly lower in the MetS group $(83.1 \pm 15.7$ vs. $89.4 \pm 14.2$, $P=0.0265)$. There was no difference between the groups in anatomical $\mathrm{CD}$ or capillary recruitment.

Table 1 Characteristics of the population

\begin{tabular}{|c|c|c|c|}
\hline & \multicolumn{2}{|c|}{ Metabolic Syndrome $(n=144)$} & \multirow[b]{2}{*}{$\mathrm{P}$} \\
\hline & No $(\mathrm{n}=108)$ & Yes $(\mathrm{n}=36)$ & \\
\hline Age (years) & $63.2 \pm 5.4$ & $62.9 \pm 5.7$ & 0.82 \\
\hline Females (\%) & 19 & 19 & - \\
\hline Smokers (\%) & 10.2 & 0 & 0.25 \\
\hline Body mass index $\left(\mathrm{kg} \mathrm{m}^{-2}\right)$ & $24.4 \pm 3.0$ & $27.9 \pm 2.6$ & $<0.0001$ \\
\hline Waist circumference $(\mathrm{cm})$ & $89.9 \pm 9.2$ & $101.1 \pm 5.7$ & $<0.0001$ \\
\hline Total body fat (\%) & $23.3 \pm 6.2$ & $29.1 \pm 6.1$ & $<0.0001$ \\
\hline Trunk fat (\%) & $23.9 \pm 6.4$ & $30.3 \pm 4.9$ & $<0.0001$ \\
\hline Visceral fat level (arbitary units) & $10.7 \pm 3.0$ & $13.4 \pm 3.5$ & $<0.0001$ \\
\hline \multicolumn{4}{|l|}{ Biological variables } \\
\hline Cholesterol (mmol I-1) & $5.8 \pm 0.9$ & $5.8 \pm 1.0$ & 0.87 \\
\hline LDL-cholesterol ( $\left.\mathrm{mmoll}^{-1}\right)$ & $3.7 \pm 0.8$ & $3.8 \pm 0.9$ & 0.88 \\
\hline HDL-cholesterol $\left(\mathrm{mmol} \mathrm{I}^{-1}\right)$ & $1.6 \pm 0.3$ & $1.3 \pm 0.3$ & $<0.0001$ \\
\hline Triglycerides $\left(\mathrm{mmol} \mathrm{I}^{-1}\right)^{\mathrm{a}}$ & $0.96(0.90 ; 1.03)$ & $1.39(1.24 ; 1.57)$ & $<0.0001$ \\
\hline Fasting glucose $\left(\mathrm{mmol}^{-1}\right)$ & $5.41 \pm 0.52$ & $5.82 \pm 0.56$ & $<0.0001$ \\
\hline Insulin $\left(\mu \mathrm{uml} \mathrm{ml}^{-1}\right)^{\mathrm{a}}$ & $4.19(3.83 ; 4.57)$ & $7.48(6.43 ; 8.70)$ & $<0.0001$ \\
\hline HOMA-IR & $1.00(0.91 ; 1.10)$ & $1.93(1.64 ; 2.26)$ & $<0.0001$ \\
\hline
\end{tabular}

Abbreviations: HDL, high-density lipoprotein; LDL, low-density lipoprotein.

Geometric mean $(95 \% \mathrm{CI})$ or means \pm s.d. are presented.

aLog-transformed variables because of skewed distribution. 
The correlation coefficients between components of the MetS and both PWV and CD measures are shown in Tables 3 and 4, respectively. Significant relationships were demonstrated between PWV and markers of abdominal fat accumulation and insulin resistance. Of the metabolic variables, fasting glucose, TGs and HOMA-IR were inversely related to functional CD. However, only fasting plasma glucose related inversely to anatomical $\mathrm{CD}$.

No association was found between $\mathrm{CD}$ and either central (all $P>0.09$ ) or peripheral BP (all $P>0.37$ ). $\mathrm{PWV}$ was unrelated to both functional and anatomical CD (all $P>0.47$ ).

In a second set of analyses, we investigated the predictors of impaired PWV $\left(\geqslant 12 \mathrm{~m} \mathrm{~s}^{-1}\right)$ and functional $\mathrm{CD}\left(\leqslant 80 \mathrm{n} \mathrm{mm}^{-2}\right)$ (Table 5). In age- and gender-adjusted analyses, for every one standard deviation increase in each continuous component of the MetS, the independent odds ratios (95\% confidence interval) for impaired PWV were 1.97 (1.29-2.99) for systolic BP, 1.55 (1.04-2.32) for WC and 1.84

Table 2 Blood pressure, heart rate, arterial stiffness and CD variables

\begin{tabular}{|c|c|c|c|}
\hline & \multicolumn{2}{|c|}{ Metabolic Syndrome $(\mathrm{n}=144)$} & \multirow[b]{2}{*}{$\mathrm{P}$} \\
\hline & No $(\mathrm{n}=108)$ & Yes $(n=36)$ & \\
\hline \multicolumn{4}{|l|}{ Peripheral (brachial) BP ( $\mathrm{mm} \mathrm{Hg}$ ) } \\
\hline Systolic BP & $120 \pm 12$ & $128 \pm 11$ & 0.0001 \\
\hline Diastolic BP & $76 \pm 7$ & $84 \pm 9$ & $<0.0001$ \\
\hline Mean BP & $91 \pm 8$ & $99 \pm 9$ & $<0.0001$ \\
\hline Pulse pressure & $43 \pm 8$ & $44 \pm 8$ & 0.486 \\
\hline \multicolumn{4}{|l|}{ Central BP ( $\mathrm{mm} \mathrm{Hg})$} \\
\hline Systolic BP & $116 \pm 13$ & $120 \pm 11$ & 0.0573 \\
\hline Diastolic BP & $80 \pm 8$ & $85 \pm 9$ & 0.0008 \\
\hline Mean BP & $95 \pm 9$ & $100 \pm 9$ & 0.006 \\
\hline Pulse pressure & $36 \pm 8$ & $35 \pm 8$ & 0.5107 \\
\hline Heart rate (beats $\mathrm{min}^{-1}$ ) & $61 \pm 10$ & $67 \pm 11$ & 0.0011 \\
\hline Pulse wave velocity $\left(\mathrm{m} \mathrm{s}^{-1}\right)^{\mathrm{a}}$ & $10.7 \pm 1.9$ & $12.2 \pm 2.8$ & 0.0047 \\
\hline Functional capillary density $\left(n \mathrm{~mm}^{-2}\right)^{a}$ & $89.4 \pm 14.2$ & $83.1 \pm 15.7$ & 0.0265 \\
\hline Anatomical capillary density $\left(n \mathrm{~mm}^{-2}\right)^{\mathrm{a}}$ & $94.4 \pm 15.9$ & $90.1 \pm 18.0$ & 0.1685 \\
\hline Capillary recruitment (\%)a & $5.8 \pm 8.8$ & $8.7 \pm 10.5$ & 0.1113 \\
\hline
\end{tabular}

Abbreviations: BP, blood pressure; $\mathrm{CD}$, capillary density

Means \pm s.d. are presented.

${ }^{a} n=141$.
(1.23-2.77) for TGs. In multivariate analyses, only systolic BP and TGs remained significant predictors of impaired PWV. For functional CD, in the age- and gender-adjusted analyses, every increase in one standard deviation in each continuous component of the MetS was associated with the following increased risks: 1.47 (1.03-2.10) for TGs and 1.74 (1.19-2.56) for fasting glucose. These two variables remained significant in the multivariate models. Consistent with the results above, none of the metabolic variables independently predicted impaired anatomical CD (data not shown).

\section{DISCUSSION}

In this study of well-characterized non-diabetic subjects, we found that subjects with the MetS exhibited macro- and microvascular impairment. We not only demonstrated increase in both peripheral and central BP, but also in PWV, consistent with increased arterial stiffness in the MetS. Similarly, subjects with the MetS had lower functional $\mathrm{CD}$, which may play an etiological role, or be a consequence to, the clustering of cardiometabolic abnormalities in these individuals.

Table 3 Age and gender-adjusted independent correlation coefficients between components of the MetS and PWV in the total sample $(n=141)$

\begin{tabular}{|c|c|c|}
\hline & \multicolumn{2}{|c|}{ Pulse wave velocity $\left(\mathrm{m} \mathrm{s}^{-1}\right)$} \\
\hline & $(\beta)$ & $\mathrm{P}$ \\
\hline Systolic BP (mm Hg) & 0.072 & $<0.0001$ \\
\hline Diastolic BP (mm Hg) & 0.095 & $<0.0001$ \\
\hline HDL-cholesterol (mmol I-1) & -0.234 & 0.6573 \\
\hline Triglycerides $\left(\mathrm{mmol} \mathrm{I}^{-1}\right)$ & 1.323 & 0.0003 \\
\hline Waist circumference $(\mathrm{cm})$ & 0.035 & 0.0751 \\
\hline Trunk fat (\%) & 0.064 & 0.0293 \\
\hline Visceral fat (arbitary units) & 0.143 & 0.0478 \\
\hline Fasting glucose $\left(\mathrm{mmol}^{-1}\right)$ & 0.590 & 0.0758 \\
\hline Fasting insulin ( $\mu \mathrm{u} \mathrm{ml}^{-1}$ ) & 0.123 & 0.0096 \\
\hline HOMA-IR & 0.485 & 0.0070 \\
\hline
\end{tabular}

Abbreviations: BP, blood pressure; HDL, high-density lipoprotein; MetS, Metabolic Syndrome; PWV, pulse-wave velocity.

Partial correlation coefficients $(\beta)$ are presented.

Table 4 Age and gender-adjusted independent correlation coefficients between independent components of the MetS and CD ( $n=141$ )

\begin{tabular}{|c|c|c|c|c|c|c|}
\hline & \multicolumn{2}{|c|}{ Functional capillary density $\left(\mathrm{n} \mathrm{mm}^{-2}\right.$ ) } & \multicolumn{2}{|c|}{ Anatomical capillary density $\left(\mathrm{n} \mathrm{mm}^{-2}\right.$ ) } & \multicolumn{2}{|c|}{ Capillary recruitment (\%) } \\
\hline & $(\beta)$ & $\mathrm{P}$ & $(\beta)$ & $P$ & $(\beta)$ & $\mathrm{P}$ \\
\hline Diastolic BP (mm Hg) & 0.064 & 0.6683 & 0.096 & 0.5647 & 0.027 & 0.7682 \\
\hline HDL-cholesterol $\left(\mathrm{mmol} \mathrm{I}^{-1}\right)$ & 6.511 & 0.0677 & 4.326 & 0.2760 & -3.360 & 0.1345 \\
\hline Triglycerides $\left(\mathrm{mmol} \mathrm{I}^{-1}\right)$ & -5.851 & 0.0208 & -2.703 & 0.3399 & 4.462 & 0.0048 \\
\hline Visceral fat (arbitary units) & -1.076 & 0.0288 & -0.537 & 0.3290 & 0.678 & 0.0284 \\
\hline Fasting glucose $\left(\mathrm{mmol} \mathrm{I}^{-1}\right)$ & -5.531 & 0.0137 & -7.374 & 0.0029 & -1.549 & 0.2764 \\
\hline 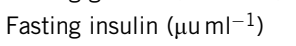 & -0.536 & 0.1005 & -0.124 & 0.7333 & 0.520 & 0.0106 \\
\hline HOMA-IR & -2.438 & 0.0472 & -1.053 & 0.4429 & 1.821 & 0.0180 \\
\hline
\end{tabular}

Abbreviations: BP, blood pressure; CD, capillary density; HDL, high-density lipoprotein; MetS, Metabolic Syndrome.

Partial correlation coefficients $(\beta)$ are presented. 
Table 5 Univariate and multivariate ORs $(95 \% \mathrm{Cl})$ for impaired PWV ( $\left.\geqslant 12 \mathrm{~m} \mathrm{~s}^{-1}, n=44\right)$ and functional CD ( $\leqslant 80$ capillaries per mm², $n=55)$, per one s.d. increase in each MetS components as a continuous variable ${ }^{a}$

\begin{tabular}{|c|c|c|c|c|}
\hline \multirow[b]{2}{*}{$\mathrm{n}=141$} & \multicolumn{2}{|c|}{$\begin{array}{c}\text { Pulse wave velocity } \geqslant 12 \mathrm{~ms}^{-1} \\
\text { OR }(95 \% \mathrm{Cl})\end{array}$} & \multicolumn{2}{|c|}{$\frac{\text { Functional } C D \leqslant 80 \text { capillaries per } \mathrm{mm}^{2}}{O R(95 \% \mathrm{Cl})}$} \\
\hline & Univariate & Multivariate & Univariate & Multivariate \\
\hline Systolic blood pressure (per 12.1-mm Hg increase) & $1.97(1.29 ; 2.99)$ & $1.65(1.11 ; 2.45)$ & $1.08(0.76 ; 1.53)$ & - \\
\hline Waist circumference (per 9.8-cm increase) & $1.55(1.04 ; 2.32)$ & - & $1.37(0.95 ; 1.96)$ & - \\
\hline HDL-cholesterol (per 0.4-mg dl-1 increase) & $0.76(0.51 ; 1.14)$ & - & $0.84(0.59 ; 1.20)$ & - \\
\hline
\end{tabular}

Abbreviations: CD, capillary density; Cl, confidence interval; HDL, high-density lipoprotein; MetS, Metabolic Syndrome; OR, odds ratio; PWV, pulse-wave velocity.

${ }^{\text {aAll }}$ models are age and gender-adjusted.

Of note, PWV and functional CD were not correlated, suggesting that different factors may contribute to their development. Although multiple common components of the MetS, namely abdominal adiposity, insulin resistance and hypertriglyceridemia, were related to both these measures, only BP was related to PWV. Interestingly, we demonstrated that a common determinant of having impaired PWV and functional CD was TG levels. We could also hypothesize that in this aging, but rather insulin-sensitive, population, early alterations of large arteries could precede the alteration of microcirculatory markers such as CD.

Most previous studies have focused on examining the effect of individual components of the MetS, such as obesity, hypertension or insulin resistance, on the microcirculation. ${ }^{21,28,29}$ Consistent with our results, it was recently reported that 36 morbidly obese normoglycemic individuals with the MetS demonstrated lower functional CD as compared with only 16 normal-weight controls. ${ }^{18}$ In our study, we found that the MetS and its components were inversely related to functional $\mathrm{CD}$. These findings suggest that cardiometabolic disturbances that define the MetS (with the exception of elevated BP) may be involved in the pathogenesis of obesity-associated skin microcirculatory dysfunction.

In a study of 28 women, although baseline resting CD was not different between the two groups, post-occlusive capillary recruitment was diminished in obese women. ${ }^{28}$ In this latter study, an inverse association was observed between systolic BP and insulin sensitivity vs. capillary recruitment. In another study, an inverse association was observed between visceral fat, measured by MRI, and capillary recruitment (but not functional CD) in 51 adults only. ${ }^{29}$ However, in this study, no association was observed between visceral fat and microvascular marker in children. An inverse association was also described between TG levels and capillary recruitment, but no data were available on the associations between baseline BP and CD. A certain level of discrepancy seems to exist between data obtained either from resting CD levels or capillary recruitment and cardiometabolic factors. One explanation may be that it is more complex to interpret capillary recruitment as a ratio (compared with baseline CD level), since it may combine measurement errors obtained from both resting and anatomical $\mathrm{CD}$ evaluation.

The pathophysiological links between the MetS and capillary rarefaction is complex and remains under debate. A few culprits have been implicated in this association, with free fatty acids (FFAs) and adipokines, such as tumor necrosis factor- $\alpha$, the most intensively studied. ${ }^{30}$ Insulin resistance, resulting in increased release of FFAs into the portal circulation, particularly from visceral fat, is likely to play a role. Indeed, in lean women, increasing FFA impairs capillary recruitment. ${ }^{31}$ Similarly, in obese women, a reduction in FFA levels improves capillary recruitment. A similar pattern was observed after insulin infusion. It has been proposed, as in muscle, ${ }^{32}$ that FFA elevation impairs insulin-mediated activation of PI3-kinase and increases the production of reactive oxygen species, leading to impairment of nitric oxide production and consequently, altered vasodilation. ${ }^{15}$

Microvascular rarefaction is also a hallmark of hypertension; the difference in arterial pressure between MetS and control subjects could contribute to the lower $\mathrm{CD}$ in patients with MetS. In addition, increased release of endothelin-1, a major vasoconstrictor substance, is likely. ${ }^{15}$ Excess secretion of proinflammatory cytokines, such as tumor necrosis factor- $\alpha$, and decreased production of anti-inflammatory adipokines, such as adiponectin, may also play a role in small-arterial vasculature dysfunction. ${ }^{15}$ In a human endothelial cell model, tumor necrosis factor- $\alpha$ has been shown to reduce the expression of endothelial NO synthase, resulting in decreased NO synthesis ${ }^{33,34}$ and increased ET-1 expression. ${ }^{35}$ In addition, sympathetic neural activation, resulting in higher vasomotor tone, may also contribute to vasoconstriction. In our study, subjects with the MetS exhibited increased heart rates as compared with subjects without the syndrome.

In accordance with our results, a study of obese Zucker rats showed that development of skeletal muscle microvessel impairments were independent of chronic elevation in mean arterial pressure. ${ }^{36}$ Indeed, microvessel density was reduced by $17 \%$ vs. lean rats, prior to any elevation in mean arterial pressure, whereas an almost fourfold higher level was observed for TG and insulin in the obese group. Microvessel rarefaction in the skeletal muscle of obese rats, manifesting metabolic abnormalities that define the MetS, does not depend on elevated mean arterial pressure, but possibly insulin resistance.

The strengths of this study include detailed metabolic phenotyping of both men and women, and simultaneous evaluation of both the large- and small-arterial tree by standardized procedures. Limitations include the small sample size, the lack of a long-term marker of glycemic status (such as Hba1c or post-load plasma glucose levels) and the cross-sectional design of the study. Therefore, causality linking the MetS to impaired capillary recruitment cannot be concluded from this study. Finally, our estimation of visceral fat level was derived from tetrapolar bio-impedance analysis, whereas the gold standard method for visceral fat level estimation is computed tomography (CT) or MRI. However, the former method involves radiation exposure and both are associated with higher costs, making it more difficult to be used in large epidemiological studies, compared with bio-impedance analysis, 
which is used more often used in such setting. Even though CT or MRI scanning offers the most accurate estimation of visceral fat, recent cross-sectional small studies have shown a good correlation in visceral fat estimation between the two methods in only Japanese populations. ${ }^{37,38}$ However, correlation between these methods has not been demonstrated in our population.

In summary, we have shown that the MetS per se is associated with both dysfunction of the large and small microcirculation, measured by both PWV and CD, in the absence of type-2 diabetes and CVD. Our findings demonstrate that vascular dysfunction in the MetS affects not only large but also small vessels and may link insulin resistance, abdominal adiposity and CVD. Future interventional studies are required to determine whether individually or simultaneously improving the components of the MetS will lead to enhancement of microcirculatory function.

\section{CONFLICT OF INTEREST}

The authors declare no conflict of interest.

\section{ACKNOWLEDGEMENTS}

Source of funding: Sébastien Czernichow holds a Fellowship awarded by the Institut Servier-France and Assistance Publique-Hôpitaux de Paris, France. Jerry Greenfield is the recipient of a Neil Hamilton Fairley Fellowship from the National Health and Medical Research Council of Australia.

1 Greenfield JR, Campbell LV. Relationship between inflammation, insulin resistance and type 2 diabetes: 'cause or effect'? Curr Diabet Rev 2006; 2: 195-211.

2 Alberti KG, Zimmet P, Shaw J. Metabolic syndrome-a new world-wide definition. A Consensus Statement from the International Diabetes Federation. Diabet Med 2006; 23: 469-480.

3 Koenig W. Cardiovascular biomarkers: added value with an integrated approach? Circulation 2007; 116: 3-5

4 Laurent S, Cockcroft J, Van Bortel L, Boutouyrie P, Giannattasio C, Hayoz D, Pannier B, Vlachopoulos C, Wilkinson I, Struijker-Boudier H. Expert consensus document on arterial stiffness: methodological issues and clinical applications. Eur Heart J 2006; 27: 2588-2605.

5 Ghiadoni L, Penno G, Giannarelli C, Plantinga Y, Bernardini M, Pucci L, Miccoli R, Taddei S, Salvetti A, Del Prato S. Metabolic syndrome and vascular alterations in normotensive subjects at risk of diabetes mellitus. Hypertension 2008; 51: 440-445.

6 Ferreira I, Henry RM, Twisk JW, Van Mechelen W, Kemper HC, Stehouwer CD. The metabolic syndrome, cardiopulmonary fitness, and subcutaneous trunk fat as independent determinants of arterial stiffness: the Amsterdam Growth and Health Longitudinal Study. Arch Intern Med 2005; 165: 875-882.

7 Safar ME, Thomas F, Blacher J, Nzietchueng R, Bureau JM, Pannier B, Benetos A. Metabolic syndrome and age-related progression of aortic stiffness. J Am Coll Cardiol 2006; 47: 72-75.

8 Greenfield JR, Samaras K, Campbell LV, Jenkins AB, Kelly PJ, Spector TD, Hayward CS Physical activity reduces genetic susceptibility to increased central systolic pressure augmentation: a study of female twins. J Am Coll Cardiol 2003; 42: 264-270.

9 Czernichow S, Bertrais S, Galan P, Blacher J, Oppert J-M, Ducimetiere P, Hercberg S, Zureik M. Body composition and fat repartition in relation to structure and function of large arteries in middle-aged adults (the SU.VI.MAX study). Int J Obes Relat Metab Disord 2005; 29: 826-832.

10 Ferreira I, Twisk JW, Van Mechelen WV, Kemper HC, Seidell JC, Stehouwer CD. Current and adolescent body fatness and fat distribution: relationships with carotid intimamedia thickness and large artery stiffness at the age of 36 years. J Hypertens 2004; 22: $145-155$

11 Ferreira I, Snijder MB, Twisk JW, Van Mechelen W, Kemper HC, Seidell JC, Stehouwer $\mathrm{CD}$. Central fat mass versus peripheral fat and lean mass: opposite (adverse versus favorable) associations with arterial stiffness? The Amsterdam Growth and Health Longitudinal Study. J Clin Endocrinol Metab 2004; 89: 2632-2639.

12 Levy BI, Schiffrin EL, Mourad JJ, Agostini D, Vicaut E, Safar ME, Struijker-Boudier HA. Impaired tissue perfusion: a pathology common to hypertension, obesity, and diabetes mellitus. Circulation 2008; 118: 968-976.

13 Levy BI, Ambrosio G, Pries AR, Struijker-Boudier HA. Microcirculation in hypertension: a new target for treatment? Circulation 2001; 104: 735-740.
14 Feihl F, Liaudet L, Waeber B, Levy BI. Hypertension: a disease of the microcirculation? Hypertension 2006; 48: 1012-1017.

15 Jonk AM, Houben AJ, de Jongh RT, Serne EH, Schaper NC, Stehouwer CD. Microvascular dysfunction in obesity: a potential mechanism in the pathogenesis of obesity-associated insulin resistance and hypertension. Physiology (Bethesda) 2007; 22: 252-260.

16 Serne EH, de Jongh RT, Eringa EC, Ijzerman RG, Stehouwer CD. Microvascular dysfunction: a potential pathophysiological role in the metabolic syndrome. Hypertension 2007; 50: 204-211.

17 Yudkin JS, Eringa E, Stehouwer CD. 'Vasocrine' signalling from perivascular fat: a mechanism linking insulin resistance to vascular disease. Lancet 2005; 365: 1817-1820.

18 Kraemer-Aguiar LG, Laflor CM, Bouskela E. Skin microcirculatory dysfunction is already present in normoglycemic subjects with metabolic syndrome. Metabolism 2008; 57 . 1740-1746.

19 Holowatz LA, Thompson-Torgerson CS, Kenney WL. The human cutaneous circulation as a model of generalized microvascular function. J Appl Physiol 2008; 105: 370-372.

20 Hercberg S, Galan P, Preziosi P, Bertrais S, Mennen L, Malvy D, Roussel AM, Favier A, Briancon S. The SU.VI.MAX study: a randomised, placebo-controlled trial of the health effects of antioxidant vitamins and minerals. Arch Intern Med 2004; 164: $1-8$.

21 Debbabi H, Uzan L, Mourad JJ, Safar M, Levy BI, Tibirica E. Increased skin capillary density in treated essential hypertensive patients. Am J Hypertens 2006; 19: 477-483.

22 Serne EH, Gans RO, ter Maaten JC, Tangelder GJ, Donker AJ, Stehouwer CD. Impaired skin capillary recruitment in essential hypertension is caused by both functional and structural capillary rarefaction. Hypertension 2001; 38: 238-242.

23 Karamanoglu M, O'Rourke MF, Avolio AP, Kelly RP. An analysis of the relationship between central aortic and peripheral upper limb pressure waves in man. Eur Heart $J$ 1993; 14: 160-167.

24 Vergnaud AC, Protogerou AD, Li Y, Czernichow S, Vesin C, Blacher J, Safar ME. Pulse pressure amplification, adiposity and metabolic syndrome in subjects under chronic antihypertensive therapy: the role of heart rate. Atherosclerosis 2007; 199: 222-229.

25 Chen CH, Nevo E, Fetics B, Pak PH, Yin FC, Maughan WL, Kass DA. Estimation of central aortic pressure waveform by mathematical transformation of radial tonometry pressure. Validation of generalized transfer function. Circulation 1997; 95: 1827-1836.

26 Sun G, French CR, Martin GR, Younghusband B, Green RC, Xie YG, Mathews M, Barron JR, Fitzpatrick DG, Gulliver W, Zhang H. Comparison of multifrequency bioelectrical impedance analysis with dual-energy $\mathrm{X}$-ray absorptiometry for assessment of percentage body fat in a large, healthy population. Am J Clin Nutr 2005; 81: 74-78.

27 Czernichow S, Bertrais S, Blacher J, Oppert J-M, Galan P, Ducimetiere P, Hercberg S, Safar M, Zureik M. Metabolic syndrome in relation to structure and function of large arteries: a predominant effect of blood pressure. A report from the SU.VI.MAX Vascular Study. Am J Hypertens 2005; 18: 1154-1160.

28 de Jongh RT, Serne EH, Ijzerman RG, de Vries G, Stehouwer CD. Impaired microvascular function in obesity: implications for obesity-associated microangiopathy, hypertension, and insulin resistance. Circulation 2004; 109: 2529-2535.

29 de Jongh RT, ljzerman RG, Serne EH, Voordouw JJ, Yudkin JS, de Waal HA, Stehouwer $C D$, van Weissenbruch MM. Visceral and truncal subcutaneous adipose tissue are associated with impaired capillary recruitment in healthy individuals. J Clin Endocrinol Metab 2006; 91: 5100-5106.

30 Wiernsperger N, Nivoit P, De Aguiar LG, Bouskela E. Microcirculation and the metabolic syndrome. Microcirculation 2007; 14: 403-438.

31 de Jongh RT, Serne EH, Ijzerman RG, de Vries G, Stehouwer CD. Free fatty acid levels modulate microvascular function: relevance for obesity-associated insulin resistance, hypertension, and microangiopathy. Diabetes 2004; 53: 2873-2882.

32 Greenfield JR, Campbell LV. Insulin resistance and obesity. Clin Dermatol 2004; 22: 289-295.

33 Rask-Madsen C, King GL. Mechanisms of disease: endothelial dysfunction in insulin resistance and diabetes. Nat Clin Pract Endocrinol Metab 2007; 3: 46-56.

34 Yoshizumi M, Perrella MA, Burnett Jr JC, Lee ME. Tumor necrosis factor downregulates an endothelial nitric oxide synthase mRNA by shortening its half-life. Circ Res 1993; 73: 205-209.

35 Mohamed F, Monge JC, Gordon A, Cernacek P, Blais D, Stewart DJ. Lack of role for nitric oxide (NO) in the selective destabilization of endothelial NO synthase mRNA by tumor necrosis factor-alpha. Arterioscler Thromb Vasc Biol 1995; 15: 52-57.

36 Frisbee JC. Hypertension-independent microvascular rarefaction in the obese Zucker rat model of the metabolic syndrome. Microcirculation 2005; 12: 383-392.

37 Demura S, Sato S. Prediction of visceral fat area at the umbilicus level using fat mass of the trunk: the validity of bioelectrical impedance analysis. J Sports Sci 2007; 25: $823-833$

38 Nagai M, Komiya H, Mori Y, Ohta T, Kasahara Y, Ikeda Y. Development of a new method for estimating visceral fat area with multi-frequency bioelectrical impedance. Tohoku J Exp Med 2008; 214: 105-112. 